\title{
COMPUTATIONAL IDENTIFICATION OF PUTATIVE DRUG TARGETS IN MALASSEZIA GLOBOSA BY SUBTRACTIVE GENOMICS AND PROTEIN CLUSTER NETWORK APPROACH
}

\author{
RAMAKRISHNAN SUBHASHINIa, MUTHUSAMY JEYAMb* \\ a,b*'Department of Bioinformatics, Bharathiar University, Coimbatore, Tamilnadu, India \\ Email: jeyam@buc.edu.in
}

Received: 09 Jun 2017 Revised and Accepted: 22 Jul 2017

\begin{abstract}
Objective: Yeast commonly causes superficial mycoses similar to the dermatophytes. Superficial mycoses were reported with an estimated incidence of $\sim 140,000,000$ cases/year worldwide and most frequently caused by Malassezia globosa and Malassezia furfur. Treatment available for these conditions is limited and with side effects. Moreover, termination of the treatment may result in the reoccurrence of the disease. The objective of this research was to identify the putative drug targets using computational approaches.
\end{abstract}

Methods: The analysis of genome sequence improves the understanding of diseases which leads to better treatment. Comparison of the genome of the pathogen with the host at the molecular level is suitable for performing the sequence based prediction of protein-protein interaction network, which also forms the basis of drug target identification leading to the discovery of new drugs for the improved treatment.

Results: Out of 100 pathways of $M$. globosa, 95 were common to the host and 5 were unique to the pathogen. Total common and unique targets from common pathways are 1704 and 300, respectively. A unique target from unique pathways and 147 from common pathways were nonhomologous targets. From this, 46 targets were screened out as essential and processed in the next phase to identify the clustered targets which resulted with three clusters based on their biological role and subcellular location.

Conclusion: In this study, putative drug targets were identified in M. globosa using in silico approaches of subtractive genomics and cluster network which will help in the next level of drug discovery such as lead identification for the novel targets.

Keywords: Malassezia globosa, Homo sapiens, Comparative genomics, Protein-protein interactions, Drug targets

(C) 2017 The Authors. Published by Innovare Academic Sciences Pvt Ltd. This is an open access article under the CC BY license (http://creativecommons.org/licenses/by/4.0/) DOI: http://dx.doi.org/10.22159/ijpps.2017v9i9.20609

\section{INTRODUCTION}

Now fungi are becoming ubiquitous in the environment and fungal infections are increasing at an alarming rate causing significant health problems [1]. The growing populations of immune compromised individuals with highly susceptibility to fungal pathogens have become a common cause of morbidity and mortality [2]. Fungal infections can be divided into systemic and superficial mycoses. Systemic or deep mycoses are able to infect internal organs. Superficial mycoses affect external part of the skin and hair, and these infections are the most common fungal diseases which affect approximately $25 \%$ of the general population worldwide [3]. Members of the genus Malassezia have become noticed as opportunistic yeasts of increasing importance in recent years by dermatologists and mycologists [4-7]. Out of 14 recognized species of Malassezia [8], a small genome size, spanning $\sim 9 \mathrm{Mb}$, Malassezia globosa is associated with skin diseases [9] such as pityriasis versicolor [10], seborrhoeic dermatitis and dandruff [11]. Treatment involves the use of ketoconazole, selenium sulfide, zinc pyrithione, ciclopirox olamine, climbazole [12] but termination of the treatment often leads to the reoccurrence of the symptoms [13].

Microorganisms are becoming resistant to multiple antibiotics, making the infections tough to eradicate [14]. Novel antimicrobials are therefore needed to combat infections. Target identification is the foremost important step in drug discovery as this whole process depends on the target and also important to battle against diseases and drug resistant microorganisms. Traditional method of drug discovery is time-consuming, labour intensive, cost effective and yield few drug targets. Novel therapeutics in areas with a high medical need is based on innovative putative drug targets, a key focus for both the pharmaceutical industry and academic research. Thus the focus in drug development has been shifted to computational subtractive genomic approach for identifying pathogen specific drug targets. Targeting the pathogen's metabolic enzymes (targets) affect only the pathogen and not the host.
Exploiting the metabolic differences between the host and the pathogen avoids host-drug interactions, i.e. the problem of crossreactivity and side effects are minimized by non-homologous proteins. Advances in computational methods, availability of complete genome and significant information in databases such as metabolic pathways, enzymes and various tools come in handy. Glycolytic pathway involved enzymes were reported as potential targets against fatal disease causing parasitic organism, Trypanosoma brucei [15]. Blocking the enzymes involved in the aspartate pathway by phytocompounds is lethal to the microorganism [16]. Lacking literature about metabolic pathway analysis based potential drug targets in M. globosa enhanced the focus on identifying the same.

\section{MATERIALS AND METHODS}

Identification of common and unique metabolic pathways

Available computational tools encompass various in silico based approaches to identify new protein targets, of which, metabolic pathway/metabolic network analysis emerged as an efficient method to identify candidate metabolic enzymes as targets. KEGG (Kyoto Encyclopedia of Genes and Genomes), a manually curated database makes a clear understanding of the biological system of any sequenced organisms. Metabolic pathways of the M. globosa and the Homo sapiens were retrieved from the KEGG database and manual comparison was done to find out the unique and common pathways of the pathogen (http://www.genome.jp/kegg).

\section{Mining of suitable proteins}

The sequences of the protein pertaining to both pathways were retrieved from the UniProt (http://www.uniprot.org) database and subjected to BLAST (Basic Local Alignment Search Tool) and sequence similarity search was performed against the host proteome database. The main objective of this step is to define the non-homologous proteins of the pathogen as it's likely to prevent 
the cross-reactivity of drug compounds with the human host proteins [17]. 'Expect' value (e-value) fixed was $<0.005$ and a minimum bit score was $>100$ to exclude the homologous sequences. Proteins which showed "hits" with the above mentioned cut-off values were considered as non-homologous proteins [18-20] and subjected to further screening process where remaining were excluded from the list.

\section{Essentiality assessment of M. globosa proteins}

DEG (Database of Essential Genes) is a database of indispensable genes from bacteria, archaea, and eukaryote organisms which support their cellular life. In order to identify the essential proteins of M. globosa, the resultant non-homologous were subjected to the protein BLAST tool and similarity search was performed against the essential eukaryotes [21] with an e-value $<0.0001$, bit score $>100$ [22] and identity greater than $30 \%$ [23].

\section{Network based targets}

Selected indispensable proteins are then subjected to STRING (Search Tool for the Retrieval of Interacting Genes/Proteins) database to construct protein-protein interaction network (http://string.embl.de) [24]. Interactors with confidence score greater than or equal to 0.700 alone included here in the protein network [25] and with low and medium confidence score were eliminated to avoid false positives and false negatives. Target protein with more interactors is considered as a metabolically active protein which could be an appropriate drug target [26,27]. The interaction network was analyzed using Cytoscape 2.8.1 [28], a package for biological network visualization and analysis. MCODE (Molecular COmplex Detection) plugin detects highly interconnected regions in the network. The optimized parameters in MCODE to analyze network includes loops, degree cutoff 2 and node score cut off 0.2 , haircut, node density cutoff $(0.1)$, k-core-2, maximum depth (100) were used to produce the best network [29].

\section{Other Important criteria to be a drug target}

The subcellular localization of the eukaryotic targets was identified by support vector machine method (SVM), ESLpred is an elegant approach (http://www.imtech.res.in/raghava/eslpred/submit.html) [30]. All the identified potential drug targets were further evaluated for its druggability by searching them against DrugBank [31] and Therapeutic Target Database (TTD) [32].

\section{RESULTS AND DISCUSSION}

\section{Common and unique targets}

Identification of putative drug targets from annotated metabolic pathways available in KEGG using subtractive genomics/ proteomics has been widely used by several researchers in bacterial pathogens [33-38]. Metabolic pathways that are present in both the host and the pathogen are identified as common pathways and those which are present only in infection causing organism but not in the host as unique pathways. Out of 100 pathways of $M$. globosa taken for the present analysis, 95 pathways are common and 5 are unique to the pathogen. The same number of unique pathways were reported from Mycoplasma hyopneumoniae in the process of identifying the drug and vaccine targets [39]. Each common pathway of the Homo sapiens and the pathogen retrieved from pathway database were compared manually and identified the common and unique targets.

In the present study, the total number of common and unique targets from common pathways are 1704 and 300, respectively. Out of 1704 common targets, 705 are involved in metabolism, 802 in genetic information processing, 17 in environmental processing and 180 in cellular processes. Total numbers of unique targets from common pathways include 177 in metabolism, 9 in genetic information processing, 53 in environmental processing and 61 in cellular processes. Five unique pathways of M. globosa are carbapenem biosynthesis, various types of $\mathrm{N}$-glycon biosynthesis, C5 branched dibasic acid metabolisms, methane metabolism, sesquiterpenoid and triterpenoid biosynthesis. In this study, unique pathways have 29 enzymes of which 28 enzymes are involved in common pathways which is in accordance with the report [40] which stated that common drug targets are also involved in the pathway unique to the pathogens of bacterial meningitis. Also, the number of drug targets identified from the common pathways of $M$. globosa were more than that identified among Streptococcus pneumonia, Neisseria meningitidis, Haemophilus influenzae type b and Staphylococcus aureus causing bacterial meningitis.

\section{Non-homologous and essential targets}

In this phase, non-homologous targets were segregated from homologous targets in the common pathways to avoid the undesirable cross reaction of the drug, thereby preventing its binding to the homologous proteins in the host, and its essentiality represents a good alternative for the development of new antifungal drugs [41]. Conserved genes in different genomes often turn out to be essential $[42,43]$. The products of essential genes that are indispensable for the growth, replication, viability or survival are important to develop drugs against the pathogen with a novel mode of action [44]. In M. globosa, a total of 147 non-homologous targets from common pathways were identified. Two unique targets were identified from unique pathways of which one target was found to be present in common pathways and the other is non-essential hence not included in the novel drug target identification. Out of 147 targets from common pathways, only 46 targets were found to be essential and the remaining were found to be non-essential [table 1].

Based on the theory that similar proteins which are essential in one eukaryotic genome may be essential for another eukaryote, hits found with DEG database with the mentioned cut-off values were expected to represent the crucial conserved essential proteins of the selected organism while remaining proteins were not, therefore excluded from the list of probable drug targets. A study showed that 57 potential drug targets from eight human fungal pathogens (Candida albicans, Aspergillus fumigatus, Blastomyces dermatitidis, Paracoccidioides brasiliensis, Paracoccidioides lutzii, Coccidioides immitis, Cryptococcus neoformans and Histoplasma capsulatum), which did not include Malassezia sp., of which only 10 were conserved as essential targets [45].

\section{Clustered targets}

Unlike the usual computational approaches, the other strategy to tackle a pathogen at the metabolic level is to identify the pathogen specific interacting enzymes [46]. Many functions within a cell are carried out by interactions between proteins being depicted by protein-protein interaction network that communicates associations between proteins. The network that finds hubs are the highly interconnected proteins or clusters playing an important role in the biological network as it is more likely to be an essential one than proteins having smaller links [47]. In the present study, 46 essential proteins of $M$. globosa studied using STRING database revealed low $(<0.004)$, medium $(0.400-0.700)$ and high confidence proteinprotein interactions $(\geq 0.700)$. The interactors with confidence score $\geq 0.700$ alone were used which goes in line with the target identification pipeline for Mycobacterium tuberculosis [48] and five non-interacting proteins of M. globosa (MGL_1691, MGL_2217, MGL 2793, MGL_1167 and MGL_2547) were excluded while selecting enzymes involved in the metabolic network as potential drug targets [fig. 1]. K-core clustering is the parameter that amplifies highly interconnected regions and removes less connected proteins that are usually a part of biomolecular interactions [49].

Interacting proteins with high confidence scores were visualized using MCODE plugin to predict protein-protein complex data set. This approach isolated densely connected regions or clusters in three steps namely (i) vector (nodes-proteins) weighting, (ii) complex prediction i.e. the protein with highest clustering density is used to seed a complex and (iii) optional post processing to filter or add proteins to the resulting complex according to certain connectivity criteria [29]. Finding precisely the important interacting enzymes as network clusters provides insights into the functions of unknown proteins [50] and as tools in the exploration of potential drug targets [46]. Indeed, the network view is increasingly being taken in many areas of applied biology including drug discovery $[51,52]$. 
Table 1: Essential proteins of Malassezia globosa

\begin{tabular}{|c|c|c|c|c|}
\hline $\begin{array}{l}\text { S. } \\
\text { No }\end{array}$ & Name of the pathways & Name of the pathogen's enzyme & MGL Seq ID & DEG ID \\
\hline & Metabolism & & & \\
\hline \multirow[t]{2}{*}{1} & Glycolysis/Gluconeogenesis/ & hexokinase & MGL_2217 & DEG20090714 \\
\hline & $\begin{array}{l}\text { Pentose phosphate pathway/Fructose } \\
\text { and Mannose Metabolism }\end{array}$ & & & DEG20010617 \\
\hline 2 & Starch and Sucrose Metabolism & trehalose 6-phosphate synthase/phosphatase & MGL_1326 & DEG20030078 \\
\hline 3 & Starch and Sucrose Metabolism & trehalose 6-phosphate synthase/phosphatase & MGL_2848 & DEG20030078 \\
\hline 4 & Starch and Sucrose Metabolism & trehalose 6-phosphate synthase & MGL_1842 & DEG20030078 \\
\hline \multirow[t]{4}{*}{5} & Starch and Sucrose Metabolism/MAPK & 1,3-beta-glucan synthase & MGL_0311 & DEG20080016 \\
\hline & signaling pathway & & & DEG20091251 \\
\hline & & & & DEG20090795 \\
\hline & & & & DEG20090494 \\
\hline \multirow[t]{2}{*}{6} & Amino Sugar and Nucleotide Sugar & chitin synthase & MGL_1195 & DEG20010039 \\
\hline & Metabolism & & & DEG20020057 \\
\hline 7 & Nitrogen Metabolism & carbonic anhydrase & MGL_1814 & DEG20090940 \\
\hline 8 & $\begin{array}{l}\text { Glycerolipid Metabolism/ } \\
\text { Glycerophospholipid Metabolism }\end{array}$ & $\begin{array}{l}\text { glycerol-3-phosphate } 0 \text { - } \\
\text { acyltransferase/dihydroxyacetone phosphate } \\
\text { acyltransferase }\end{array}$ & MGL_2378 & DEG20090920 \\
\hline 9 & $\begin{array}{l}\text { Glycerophospholipid Metabolism } \\
\text { Glycine, Serine and Threonine Metabolism }\end{array}$ & $\begin{array}{l}\text { CDP-diacylglycerol---serine 0-phosphatidyl } \\
\text { transferase }\end{array}$ & MGL_2439 & DEG20091203 \\
\hline 10 & Glycine, Serine and Threonine Metabolism & homoserine kinase & MGL_3519 & DEG20090876 \\
\hline 11 & $\begin{array}{l}\text { Glycine, Serine and Threonine } \\
\text { Metabolism/Cysteine and Methionine } \\
\text { metabolism/Lysine Biosynthesis }\end{array}$ & aspartate kinase & MGL_4205 & DEG20090951 \\
\hline 12 & $\begin{array}{l}\text { Glycine, Serine and Threonine } \\
\text { Metabolism/Cysteine and Methionine } \\
\text { metabolism/Lysine Biosynthesis }\end{array}$ & aspartate-semialdehyde dehydrogenase & MGL_3740 & DEG20091259 \\
\hline 13 & Cysteine and Methionine metabolism & homoserine 0 -acetyltransferase & MGL_2541 & DEG20080024 \\
\hline 14 & Cysteine and Methionine metabolism & homoserine 0 -acetyltransferase & MGL_3917 & DEG20080024 \\
\hline 15 & $\begin{array}{l}\text { Valine, Leucine and Isoleucine } \\
\text { biosynthesis/Pantothenate and CoA } \\
\text { Biosynthesis }\end{array}$ & ketol-acid reductoisomerase & MGL_3299 & DEG20010747 \\
\hline 16 & $\begin{array}{l}\text { Valine, Leucine and Isoleucine } \\
\text { biosynthesis } \\
\text { Pantothenate and CoA Biosynthesis }\end{array}$ & dihydroxy-acid dehydratase & MGL_3741 & DEG20010579 \\
\hline 17 & Histidine Metabolism & $\begin{array}{l}\text { phosphoribosyl-ATP } \\
\text { pyrophosphohydrolase/phosphoribosyl-AMP } \\
\text { cyclohydrolase/histidinol dehydrogenase }\end{array}$ & MGL_2613 & DEG20030044 \\
\hline 18 & Histidine Metabolism & $\begin{array}{l}\text { phosphoribosylformimino-5-aminoimidazole } \\
\text { carboxamide ribotide isomerase }\end{array}$ & MGL_2036 & DEG20030128 \\
\hline 19 & Histidine Metabolism & HisF/His H/glutamine amidotransferase/cyclase & MGL_0140 & DEG20030249 \\
\hline 20 & Histidine Metabolism & imidazoleglycerol-phosphate dehydratase & MGL_3523 & DEG20080003 \\
\hline 21 & Histidine Metabolism & histidinol-phosphatase (PHP family) & MGL_3105 & DEG20091091 \\
\hline \multirow[t]{2}{*}{22} & Phenyl Alanine, Tyrosine and Tryptophan & pentafunctional AROM polypeptide & MGL_3989 & DEG20090474 \\
\hline & Biosynthesis & & & DEG20030155 \\
\hline \multirow[t]{2}{*}{23} & Phenyl Alanine, Tyrosine and Tryptophan & tryptophan synthase & MGL_0012 & DEG20080034 \\
\hline & $\begin{array}{l}\text { Biosynthesis/Glycine, Serine and } \\
\text { Threonine Metabolism }\end{array}$ & & & DEG20090244 \\
\hline \multirow[t]{3}{*}{24} & Phenyl Alanine, Tyrosine and Tryptophan & anthranilate synthase/indole-3-glycerol phosphate & MGL_0538 & DEG20091201 \\
\hline & Biosynthesis & synthase/phosphoribosyl anthranilate isomerase & & DEG20030117 \\
\hline & & & & DEG20090948 \\
\hline \multirow[t]{2}{*}{25} & Phenyl Alanine, Tyrosine and Tryptophan & chorismate synthase & MGL_1168 & DEG20091208 \\
\hline & Biosynthesis & & & DEG20030052 \\
\hline 26 & $\begin{array}{l}\text { Phenyl Alanine, Tyrosine and Tryptophan } \\
\text { Biosynthesis }\end{array}$ & anthranilate phosphoribosyltransferase & MGL_1155 & DEG20091019 \\
\hline 27 & $\begin{array}{l}\text { Phenyl Alanine, Tyrosine and Tryptophan } \\
\text { Biosynthesis }\end{array}$ & chorismate mutase & MGL_0402 & DEG20090359 \\
\hline 28 & Thiamine Metabolism & $\begin{array}{l}\text { hydroxymethylpyrimidine/phosphomethylpyrimidine } \\
\text { kinase }\end{array}$ & MGL_1338 & DEG20090945 \\
\hline 29 & Riboflavin Metabolism & GTP cyclohydrolase II & MGL_1904 & DEG20090158 \\
\hline 30 & Riboflavin Metabolism & $\begin{array}{l}\text { 2,5-diamino-6-(ribosylamino)-4(3H)-pyrimidinone } 5 \text { '- } \\
\text { phosphate reductase }\end{array}$ & MGL_2361 & DEG20010061 \\
\hline \multirow[t]{2}{*}{31} & Riboflavin Metabolism & 3,4-dihydroxy 2-butanone 4-phosphate synthase & MGL_0570 & DEG20090968 \\
\hline & & & & DEG20010261 \\
\hline 32 & Riboflavin Metabolism & 6,7-dimethyl-8-ribityllumazine synthase & MGL_0356 & DEG20090651 \\
\hline \multirow{2}{*}{33} & Riboflavin Metabolism & riboflavin synthase & MGL_0273 & DEG20010082 \\
\hline & & & & DEG20091197 \\
\hline 34 & Vitamin B6 Metabolism & 5'-phosphate synthase pdxT subunit & MGL_1990 & DEG20030345 \\
\hline 35 & Nicotinate and Nicotinamide Metabolism & nicotinate phosphoribosyltransferase & MGL_3226 & DEG20090331 \\
\hline 36 & Biotin Metabolism & biotin synthase & MGL_1037 & DEG20030139 \\
\hline 37 & Folate Biosynthesis & 2-amino-4-hydroxy-6- & MGL_1723 & DEG20090637 \\
\hline
\end{tabular}


$38 \quad$ Folate Biosynthesis

39 Terpenoid Backbone Biosynthesis

Genetic Information Processing

40 Basal Transcription Factors

41 Ribosome

42 Ribosome

43 Protein export

Environmental Information Processing

44 MAPK signaling pathway

45 MAPK signaling pathway

Cellular Processes

46 Endocytosis hydroxymethyldihydropteridine

diphosphokinase/dihydropteroate synthase

para-aminobenzoate synthetase

phosphomevalonate kinase

transcription initiation factor TFIIF subunit alpha

small subunit ribosomal protein S10

large subunit ribosomal protein L28

signal peptidase complex subunit 3

DEG20010889

DEG20030117

DEG20090948

DEG20091201

MGL_2793 DEG20010822

MGL_2547 DEG20091239

MGL_1513 DEG20010163

DEG20090970

MGL_3122 DEG20090779

MGL_1691 DEG20010691

DEG20090095

osomolarity two-component system, phosphorelay $\quad$ MGL_3758 DEG20010156

intermediate protein YPD1

osomolarity two-component system, response regulator, SSK1

MGL_0602 DEG20010520

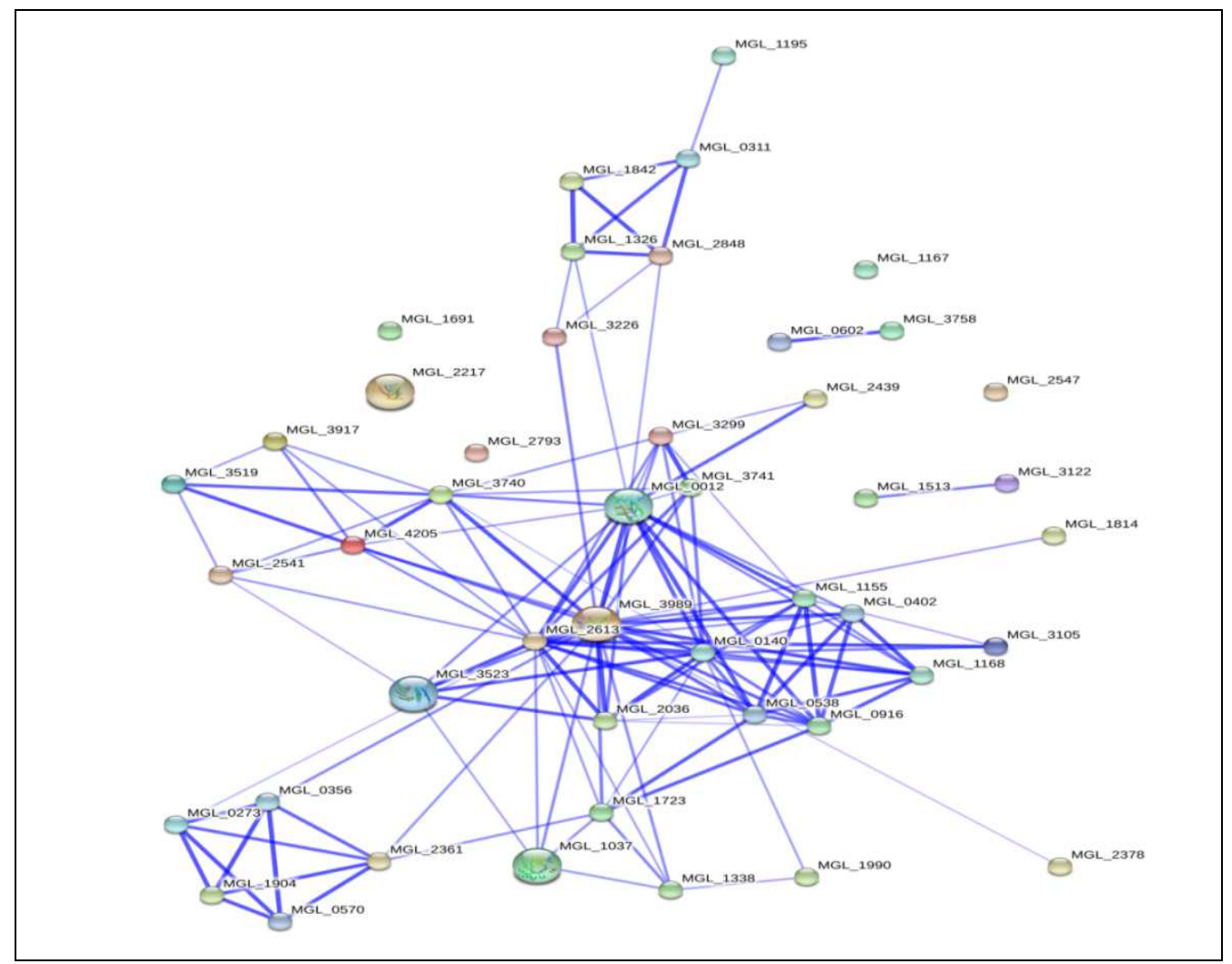

Fig. 1: Interacting and non-interacting proteins of Malassezia globosa

Four clusters were resulted from the entire network as the objective is to group proteins that are related by functions and have a significant biological process. High score of a cluster represents an important network region because the components of this molecular complex function towards the same biological goal that provides another level of functional annotation [47]. Even the node of the least score cluster found to be significant in some case [53]. Here, the first cluster involves most enzymes that participate in amino acid biosynthesis, an important pathway in identifying putative drug targets since the amino acid biosynthesis pathway had been already validated by the pathway comparison between aspergillosis causing pathogen and human proteins which revealed eight enzymes as potential targets for drug design where most of them were from this pathway [54]. Also, one of these clustered targets (MGL_0916) found to be participating in the metabolism of co-factor and vitamins, especially in the folate biosynthesis. The first cluster score is greater than 5 with 7 nodes (interactors) and 21 edges (interactions). The clustered targets given in the order of node IDs namely paraaminobenzoate synthetase, glutamine amidotransferase, anthranilate phosphoribosyl transferase, anthranilate synthase/ indole-3-glycerol phosphate synthase/phosphoribosyl anthranilate isomerase, phosphorribosyl-ATP pyrophosphohydrolase/ phosphoribosyl-AMP cyclohydrolase/ histidinol dehydrogenase, tryptophan synthase, pent-afunctional AROM polypeptide were predicted to be present in mitochondria, a specialized organelle that regulate metabolism.

Fungal pathogen specific mitochondrial proteins play a key role in virulence, adaptation to stress, cell wall synthesis and antifungal drug tolerance. Further, lacking homologs in human is an added advantage of antifungal therapy as stated by Calderone et al. [55]. 
The cluster 2 consists of 5 nodes and 7 edges with the cluster score of 3.3. Targets namely 3,4-dihydroxy 2-butanone 4-phosphate synthase, GTP cyclohydrolase II,6,7-dimethyl-8-ribityllumazine synthase, 2,5-diamino-6-(ribosylamino)-4(3H)-pyrimidinone 5'phosphate reductase and riboflavin synthase of this cluster belong to the pathogen pathway of metabolism of co-factor and vitamins. The subcellular location of these targets varies viz MGL_0570 and MGL_1904 were predicted as nuclear, MGL_0356 as cytoplasmic, MGL_2361 as mitochondrial and MGL_0273 as extracellular enzymes. The cluster 3 with the score 2.4 includes 4 nodes and 6 edges, and these targets are involved in carbohydrate metabolism and signal transduction pathway. Likewise, in another analysis, six targets from the carbohydrate metabolism and some more targets from the other pathways were reported as essential for the bacterial organism surveillance and multiplication [56], and enzymes involved in carbohydrate metabolism as important drug targets in Leishmania parasites [57]. The cellular location of three enzymes (MGL_2848=trehalose 6-phosphate synthase/phosphatase; MGL=trehalose 6-phosphate synthase/phosphatase; and MGL=trehalose 6-phosphate synthase) predicted to be nuclear except MGL_0311 (1,3-beta-glucan synthase), an extracellular enzyme.

The least score (1.5) of this analysis is for cluster4 with the equal number of nodes and edges (3) and the targets were identified as cytoplasmic proteins such as aspartate kinase, homoserine kinase and aspartate-semialdehyde dehydrogenase involved in amino acid metabolism. In the study of infectious pathogens such as Chlamydophila pneumoniae, Porphyromonas gingivalis and Helicobacter pylori causing Atherosclerosis, a total of 14 interacting drug targets were predicted [58].
In addition, the other vital properties which are significant to be potential drug targets are druggability, molecular weight and subcellular localization of these clusters [59] and the results of this study is given in table 2. The non-hit proteins of drug bank and therapeutic target database could be novel targets. In the present study, 2 proteins with hits were considered as druggable and the remaining may be the novel putative drug targets as stated in an earlier report [60]. Even lower molecular weight protein helped in mapping the small molecule binding and aids more specifically in developing the high-affinity inhibitors [61]. Here, molecular size of the enzymes found to be greater than 100 are more likely to represent essential and considered as significant drug targets [62].

Enzymes from different metabolic pathways are important to identify novel drug targets. Eighty-six targets from amino acid metabolism and forty-one from vitamin and cofactor biosynthetic pathways and forty-eight from carbohydrate metabolism were identified as potential drug targets in Mycobacterium tuberculosis through the computational analysis [63]. Researchers interested in virology created the Chikungunya database containing its virulent strains and the role of drug target in the infection [64]. Targets are helpful in finding out suitable ligands or hits against disease causing organisms as in the case of Klebsiella pneumonia [65] and Mycobacterium tuberculosis [66]. Mahendran et al. [67] reported nine enzymes from the investigation of metabolic pathways where targets lacking three-dimensional structure were modeled in silico and identified potential ligands against Treponema pallidum. From the present analysis, 19 targets have been suggested as potential drug targets to combat infections caused by M. globosa.

Table 2: Clustered targets of the pathogen

\begin{tabular}{|c|c|c|c|c|c|c|c|c|}
\hline Cluster & Score & Nodes & Edges & Node Identifications & $\begin{array}{l}\text { Subcellular } \\
\text { location of the } \\
\text { protein }\end{array}$ & $\begin{array}{l}\text { Molecular } \\
\text { size }\end{array}$ & $\begin{array}{l}\text { Existing/Novel } \\
\text { drug targets }\end{array}$ & Pathways Involved \\
\hline \multirow[t]{7}{*}{1} & \multirow[t]{7}{*}{5.25} & \multirow[t]{7}{*}{7} & \multirow[t]{7}{*}{21} & MGL_0916 & Mitochondria & 464 & No hits & \multirow{7}{*}{$\begin{array}{l}\text { Metabolism of } \\
\text { co-factor and vitamins } \\
\text { and amino acid } \\
\text { metabolism }\end{array}$} \\
\hline & & & & MGL_0140 & Mitochondria & 576 & No hits & \\
\hline & & & & MGL_1155 & Mitochondria & 413 & Yes & \\
\hline & & & & MGL_0538 & Mitochondria & 502 & No hits & \\
\hline & & & & MGL_2613 & Mitochondria & 884 & No hits & \\
\hline & & & & MGL_0012 & Mitochondria & 660 & No hits & \\
\hline & & & & MGL_3989 & Mitochondria & 1611 & No hits & \\
\hline \multirow[t]{5}{*}{2} & \multirow[t]{5}{*}{3.333} & \multirow[t]{5}{*}{5} & \multirow[t]{5}{*}{10} & MGL_0570, & Nuclear & 172 & No hits & \multirow{5}{*}{$\begin{array}{l}\text { Metabolism of } \\
\text { co-factor and vitamins }\end{array}$} \\
\hline & & & & MGL_1904, & Nuclear & 455 & No hits & \\
\hline & & & & MGL_0356, & Cytoplasmic & 171 & Yes & \\
\hline & & & & MGL_2361, & Mitochondria & 245 & No hits & \\
\hline & & & & MGL_0273 & Extracellular & 293 & No hits & \\
\hline \multirow[t]{4}{*}{3} & \multirow[t]{4}{*}{2.4} & \multirow[t]{4}{*}{4} & \multirow[t]{4}{*}{6} & MGL_0311, & Extracellular & 1311 & No hits & \multirow{4}{*}{$\begin{array}{l}\text { Carbohydrate } \\
\text { metabolism and signal } \\
\text { transduction pathway }\end{array}$} \\
\hline & & & & MGL_2848, & Nuclear & 1317 & No hits & \\
\hline & & & & MGL_1842, & Nuclear & 523 & No hits & \\
\hline & & & & MGL_1326 & Nuclear & 680 & No hits & \\
\hline \multirow[t]{3}{*}{4} & \multirow[t]{3}{*}{1.5} & \multirow[t]{3}{*}{3} & \multirow[t]{3}{*}{3} & MGL_4205, & Cytoplasm & 502 & No hits & \multirow[t]{3}{*}{ Amino acid metabolism } \\
\hline & & & & MGL_3519, & Cytoplasm & 355 & No hits & \\
\hline & & & & MGL_3740 & Cytoplasm & 367 & No hits & \\
\hline
\end{tabular}

Bold indicates existing druggable targets

\section{CONCLUSION}

Synthetic antifungal compounds which are the leading candidates among various treatment options have poor clinical efficacy as they are unable to prevent the recurrence. Such complications prompted the search of new antifungals to treat the clinical condition caused by $M$. globosa. Computational method reduces time in the identification of putative drug targets from important pathways. Designing target based drug reduces off-target side effects. Therefore the current research work focused on identifying the potential drug targets in M. globosa which may be the first study that would be helpful to explore new and efficient compounds in target based drug discovery for the treatment of the organism. Here, a total of 19 drug targets that include 2 druggable and 17 novel putative drug targets were identified by comparative genomics and cluster network approach thereby opening a new area in antifungal drug discovery through an interdisciplinary endeavour.

\section{ACKNOWLEDGEMENT}

We acknowledge the Bharathiar University for providing us with the needed infrastructure.

\section{CONFLICT OF INTERESTS}

No conflict of interest

\section{AUTHOR CONTRIBUTION}

Both authors contributed equally to this work 


\section{REFERENCES}

1. Fleming RV, Walsh TJ, Anaissie EJ. Emerging and less common fungal pathogens. Infectious Diseases Clin North Am 2002;16:915-33.

2. Garbino J, Kolarova L, Lew D, Hirschel B, Rohner P. Fungemia in HIV-infected patients: a 12 y study in a tertiary care hospital. AIDS Patient Care STDs 2001;15:407-10.

3. Havlickova B, Czaika VA, Friedrich M. Epidemiological trends in skin mycoses worldwide. Mycoses 2008;51:2-15.

4. Batra R, Boekhout T, Gueho E, Cabanes FJ, Dawson TL, Gupta AK. Malassezia Baillon, emerging clinical yeasts. FEMS Yeast Res 2005;5:1101-3.

5. Moniri R, Nazeri M, Amiri S, Asghari B. Isolation and identification of Malassezia spp. in pytiriasis versicolor in Kashan, Iran. Pak J Med Sci 2009;25:837-40.

6. Byung HO, Yang EL, Yong BC, Kyu JA. Epidemiologic study of Malassezia yeasts in seborrheic dermatitis patients by the analysis of 26S rDNA PCR-RFLP. Ann Dermatol 2010; 22:149-55.

7. Sampurna BP, Atreyi C, Anita N, Maitrayee B, Rina G, Bandopadhyay $\mathrm{M}$, et al. A study of the prevalence of different species of Malassezia causing pityriasis versicolor and sites of distribution of lesion in a tertiary care hospital in Kolkatta, India. Int J Curr Microbiol Appl Sci 2015;4:471-8.

8. Hort W, Mayser P. Malassezia virulence determinants. Curr Opin Infect Dis 2011;24:100-5.

9. Gueho E, Boekhout T, Ashbee HR, Guillot J, Van Belkurn A, Faergemann J. The role of Malassezia species in the ecology of human skin and as pathogens. Med Mycol 1998;36:220-9.

10. Crespo Erchiga V, Ojeda Martos A, Vera Casano A, Crespo Erchiga A, Sanchez Fajardo F. Malassezia globosa as the causative agent of pityriasis versicolor. $\mathrm{Br} \mathrm{J}$ Dermatol 2000;143:799-803.

11. Thomas L, Dawson JR. Malassezia globosa and restricta: Breakthrough understanding of the etiology and treatment of dandruff and seborrheic dermatitis through whole genome analysis. J Invest Dermatol 2007;12:15-9.

12. Baran R, Maibach HI. editors. Schwartz JR, Cardin CW, Dawson TL. Dandruff and seborrheic dermatitis. Textbook of Cosmetic Dermatology London: UK; 2004. p. 259-72.

13. Crespo Erchiga V, Delgado Florencio V. Malassezia species in skin diseases. Curr Opin in Infect Dis 2002;15:133-42.

14. Roberts L, Simpson S. Drug Resistance. Deadly defiance. Introduction to special Issue. Science 2008;321:55.

15. Christophe LM, Verlinde CL, Hannaert V, Blonski C, Willson M, Perie JJ, et al. Glycolysis as a target for the design of new antitrypanosome drugs. Drug Resist Updates 2001;4:50-65.

16. Oviya IR, Sharanya M, Jeyam M. Phytocompounds from Sphaeranthus indicus and Wrightia tinctoria targeting fungal aspartate pathway-an in silico evaluation. Adv Biomed Pharm 2015;2:13-21.

17. Sarkar M, Maganti L, Ghoshal N, Dutta C. In silico quest for putative drug targets in Helicobacter pylori HPAG1:molecular modeling of candidate enzymes from lipopolysaccharide biosynthesis pathway. J Mol Model 2012;18:1855-66.

18. Collins JF, Coulson AF, Lyall A. The significance of protein sequence similarities. CABIOS Comput Appl Biosci 1988;4:67-71.

19. Pearson WR. Comparison of methods for searching protein sequence databases. Protein Sci 1995;4:1145-60.

20. Pearson WR. Effective protein sequence comparison. Methods Enzymol 1996;266:227-58.

21. Luo H, Lin Y, Gao F, Zhang CT, Zhang R. DEG 10, an update of the database of essential genes that includes both protein coding genes and noncoding genomic elements. Nucleic Acids Res 2014;42:574-80.

22. Jadhav A, Ezhilarasan V, Prakash Sharma O, Pan A. ClostridiumDT(DB): a comprehensive database for potential drug targets of Clostridium difficile. Comput Biol Med 2013;43:362-7.

23. Aditya NS, Rakesh A, Qamar R, Nidhi T. Subtractive genomics approach for in silico identification and characterisation of novel drug targets in Neisseria Meningitis serogroup B. J Comput Sci Syst Biol 2009;2:255-8.

24. Zhang R, Lin Y. DEG 5.0, a database of essential genes in both prokaryotes and eukaryotes. Nucleic Acids Res 2009;37:455-8.
25. Raman K, Yeturu K, Chandra N. target TB: a target identification pipeline for Mycobacterium tuberculosis through an interactome, reactome and genome-scale structural analysis. BMC Syst Biol 2008;2:1-21.

26. Kushwaha SK, Shakya M. Protein interaction network analysisapproach for potential drug target identification in Mycobacterium tuberculosis. J Theor Biol 2010;262;284-94.

27. Cui T, Zhang L, Wang X, He ZG. Uncovering new signaling proteins and potential drug targets through the interactome analysis of Mycobacterium tuberculosis. BMC Genomics 2009;10:1-10.

28. Smoot ME, Ono K, Ruscheinski J, Wang PL, Ideker T. Cytoscape 2.8:new features for data integration and network visualization. Bioinformatics 2011;27:431-2.

29. Vipin G, Shazia H, Sood U, Jack AG, Meenakshi R, Ken F, et al. Comparative genomic analysis of novel Acinetobacter symbionts: a combined system biology and genomics approach. Nat: Sci Reports 2016;6:1-12.

30. Bhasin M, Raghava GPS. ESLpred: SVM based method for subcellular localization of eukaryotic proteins using dipeptide composition and PSI-BLAST. Nucleic Acids Res 2004;32:414-9.

31. Knox C, Law V, Jewison T, Liu P, Ly S, Frolkis A, et al. DrugBank 3.0:a comprehensive resource for 'omics' research on drugs. Nucleic Acids Res 2011;39:1035-41.

32. Chen X, Ji ZL, Chen YZ. TTD: Therapeutic target database. Nucleic Acids Res 2002;30:412-5.

33. Barh D, Sandeep T, Neha J, Amjad A, Anderson, Amarendra NM, et al. In silico subtractive genomics for target identification in human bacterial pathogens. Drug Dev Res 2011;72:162-77.

34. Madagi S, Patil VM, Sadegh S, Singh AK, Garwal B, Banerjee A, et al. Identification of membrane associated drug targets in Borrelia burgdorferi ZS7-subtractive genomics approach. Bioinformation 2011;6:356-9.

35. Butt AM, Tahir S, Nasrullah I, Idrees M, Lu J, Tong Y. Mycoplasma genitalium: a comparative genomics study of metabolic pathways for the identification of drug and vaccine targets. J Mol Epidemiol Evolutionary Genetics Infectious Diseases 2012;12:53-62.

36. Arvind A, Jain V, Saravanan P, Mohan CG. Uridine monophosphate kinase as a potential target for tuberculosis: from target to lead identification. Interdiscip Sci: Comput Life Sci 2013;5:296-311.

37. Hosen MI, Tanmoy AM, Mahbuba DA, Salma U, Nazim M, Islam MT, et al. Application of a subtractive genomics approach for Insilico identification and characterization of novel drug targets in Mycobacterium tuberculosis F11. Interdiscip Sci: Comput Life Sci 2014;6:48-56.

38. Singh S, Bukhsh Singh D, Singh A, Gautam B, Tam G, Dwidevi S, et al. An approach for identification of novel drug targets in Streptococcus pyogenes SF370 through pathway analysis. Interdiscip Sci: Comput Life Sci 2016;3:388-94.

39. Damte D, Suh J, Lee S, Yohannes SB, Akil Hossain, Park S. Putative drug and vaccine target protein identification using comparative genomic analysis of KEGG annotated metabolic pathways of Mycoplasma hyopneumoniae. Genomics 2013;102:47-56.

40. Munikumar M, Vani Priyadarshini I, Pradhan D, Sandeep S, Umamaheswari A, Bhuma Vengamma. In silico identification of common putative drug targets among the pathogens of bacterial meningitis. Biochem Anal Biochem 2012;1:1-7.

41. Li X, Hou Y, Yue L, Liu S, Du J, Sun S. Potential targets for antifungal drug discovery based on growth and virulence in Candida albicans. Antimicrob Agents Chemother 2015;59:5885-91.

42. Kobayashi K, Ehrlich SD, Albertini A, Amati G, Andersen KK, Arnaud M, et al. Essential Bacillus subtilis genes. Proc Natl Acad Sci 2003;100:4678-83.

43. Galperin MY, Koonin EV. Conserved hypothetical proteins: prioritization of targets for experimental study. Nucleic Acids Res 2004;32:5452-63.

44. Goutam M, Arunima G, Sourav S, Paramita S, Naboneeta S. In silico identification of potential therapeutic targets in the human pathogen Neisseria Meningitidis MC58. Int J Pharm Eng 2012;1:1-4. 
45. Abadio AKR, Kioshima ES, Teixeria MM, Martins NF, Maigret B, Felipe MS. Comparative genomics allowed the identification of drug targets against human fungal pathogens. BMC Genomics 2011;12:1-10

46. Kaltdorf M, Srivastava M, Gupta SK, Liang C, Binder J, Dietl AM, et al. Systematic identification of antifungal drug targets by a metabolic network approach. Front Mol Biosci 2016;3:1-19.

47. Jeong $\mathrm{H}$, Mason SP, Barbasi AL, Oltavi ZN. Lethality and centrality in protein networks. Nature 2001;411:41-2.

48. Raman K, Yeturu K, Chandra N. target TB: a target identification pipeline for Mycobacterium tuberculosis through an interactome, reactome and genome-scale structural analysis. BMC Syst Biol 2008;2:1-21.

49. Ho Y, Gruhler A, Heilbut A, Bader GD, Moore L, Adams SL. Systematic identification of protein complexes in Saccharomyces cerevisiae by mass spectrometry. Nature 2002;415:180-3.

50. Pavan G, Manjunatha H, Sharath P. Cluster analysis of proteinprotein interaction network of Mycobacterium tuberculosis during host infection. Adv Biores 2015;6:38-46.

51. Klipp E, Wade RC, Kummer U. Biochemical network-based drug-target prediction. Curr Opin Biotechnol 2010;21:511-6.

52. Pujol A, Mosca R, Farres J, Aloy P. Unveiling the role of network and systems biology in drug discovery. Trends Pharmacol Sci 2010;31:115-23.

53. Kumar HSS, Kumar V, Pattar S, Telkar S. Towards the construction of an interactome for a human WD40 protein family. Bioinformation 2016;12:54-61.

54. Morya VK, Kumari S, Kim E. Imperative pathway analysis to identify the potential drug target for Aspergillus infection. Int J Latest Trends Computing 2011;2:178-82.

55. Calderone R, Li D, Traven A. System-level impact of mitochondria on fungal virulence: to metabolism and beyond. FEMS Yeast Res 2015;15:1-11.

56. Murima P, McKinney JD, Pethe K. Targeting bacterial central metabolism for drug development. Chem Biol 2014;21:1423-32.

57. Myler PJ, Fasel N. editors. Opperdoes FR, Michels PA. The metabolic repertoire of Leishmania and implications for drug discovery. U. K Caister: Academic Press; 2008. p. 123-58.

58. Hema K, Priyadarshini IV, Pradhan D, Munikumar M, Sandeep S. Identification of putative drug targets and vaccine candidates for pathogens causing atherosclerosis. Biochem Anal Biochem 2015;4:1-9.

59. Sharma OP, Kumar MS. Essential proteins and possible therapeutic targets of Wolbachia endosymbiont and development of FiloBase-a comprehensive drug target database for Lymphatic filariasis. Sci Rep 2016;6:1-11.

60. Parvege M, Rahman M, Hossain MS. Genome-wide analysis of Mycoplasma hominis for the identification of putative therapeutic targets. Drug Target Insights 2014;8:51-62.

61. Tolkatchev D, Shaykhutdinov R, Xu P, Plamondon J, Watson DC, Young NM, et al. Three-dimensional structure and ligand interactions of the low molecular weight protein tyrosine phosphatase from Campylobacter jejuni. Protein Sci 2006;15:2381-94.

62. Chordia N, Lakhawat K, Kumar A. Identification of drug target properties and its validation on Helicobacter pylori. Can J Biotech 2017;1:44-9.

63. Anishetty S, Pulimi M, Pennathur G. Potential drug targets in Mycobacterium tuberculosis through metabolic pathway analysis. Comput Biol Chem 2005;29:368-78.

64. Kori P, Madagi SB. Chikungunya drug target database: a comprehensive database of chikungunya drug targets. Asian J Pharm Clin Res 2016;9:134-7.

65. Bhaskar BV, Chandra Babu TM, Rajendra W. Homology modeling and development of dihydrodipicolinate reductase inhibitors of Klebsiella pneumonia: a computational approach. Int J Curr Pharm Res 2016;8:71-6.

66. Daisy P, Pon Nivedha R, Helen Bakiya. In silico drug designing approach for biotin protein ligase of Mycobacterium tuberculosis. Asian J Pharm Clin Res 2013;6:103-7.

67. Mahendran R, Jeyabasker S, Manoharan S, Francis A, Shah U. In silico metabolic pathway analysis and docking analysis of Treponema pallidium subs. Pallidium Nichols for potential drug targets. Asian J Pharm Clin Res 2017;10:261-4.

\section{How to cite this article}

- Ramakrishnan Subhashini, Muthusamy Jeyam. Computational identification of putative drug targets in Malassezia globosa by subtractive genomics and protein cluster network approach. Int J Pharm Pharm Sci 2017;9(9):215-221. 